\title{
战略性关键矿产研究现状与科学前沿
}

侯增谦 $^{1 \dagger^{*}}$, 陈骏 ${ }^{2 \dagger}$, 翟明国 ${ }^{3 \dagger}$

1. 中国地质科学院地质研究所, 北京 100037 ;

2. 南京大学内生金属矿床成矿机制研究国家重点实验室, 地球科学与工程学院, 南京 210023;

3. 中国科学院地质与地球物理研究所, 岩石圈演化国家重点实验室, 北京 100029

$\dagger$ 同等贡献

*联系人, E-mail: houzengqian@ 126.com

\section{Current status and frontiers of research on critical mineral resources}

\author{
Zengqian $\mathrm{Hou}^{1+*}$, Jun $\mathrm{Chen}^{2 \dagger} \&$ Mingguo $\mathrm{Zhai}^{3 \dagger}$ \\ ${ }^{1}$ Institute of Geology, Chinese Academy of Geological Sciences, Beijing 100037, China; \\ ${ }^{2}$ State Key Laboratory for Mineral Deposits Research, School of Earth Sciences and Engineering, Nanjing University, Nanjing 210023, China; \\ ${ }^{3}$ State Key Laboratory of Lithospheric Evolution, Institute of Geology and Geophysics, Chinese Academy of Sciences, Beijing 100029, China \\ $\dagger$ Equally contributed to this work \\ * Corresponding author, E-mail: houzengqian@126.com
}

doi: 10.1360/TB-2020-1417

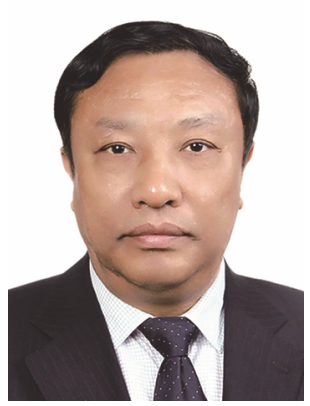

\section{侯增谦}

中国地质科学院地质研究所 研究员, 中国科学院院士, 发展中国家科学院院士, 国 家重点基础研究发展计划 (973 计划)及重点研发计划深 地资源项目首席科学家。长 期从事金属成矿理论与资源 勘查技术研究，获国家科技 进步奖特等奖、国家科技进 步奖一等奖、国家自然科学 二等奖各 1 项.

(ㅇ) 2020 《中国科学》杂志社
关键矿产或关键金属是国际上最近提出的资源概念，指的是现今社会必 需、但安全供应存在较高风险的一类矿产的总称, 主要包括稀有金属(如 $\mathrm{Li}$ 、 $\mathrm{Be} 、 \mathrm{Rb} 、 \mathrm{Cs} 、 \mathrm{Nb} 、 \mathrm{Ta} 、 \mathrm{Zr} 、 \mathrm{Hf} 、 \mathrm{~W} 、 \mathrm{Sn}$ 等)、稀土金属(La、Ce、Pr、Nd、Sm、 $\mathrm{Eu} 、 \mathrm{Gd} 、 \mathrm{~Tb} 、 \mathrm{Dy} 、 \mathrm{Ho} 、 \mathrm{Er} 、 \mathrm{Tm} 、 \mathrm{Yb} 、 \mathrm{Lu} 、 \mathrm{Sc} 、 \mathrm{Y}) 、$ 稀散金属 $(\mathrm{Ga} 、 \mathrm{Ge} 、 \mathrm{Se} 、$ $\mathrm{Cd} 、 \mathrm{In} 、 \mathrm{Te} 、 \mathrm{Re} 、 \mathrm{Tl})$ 和部分稀贵金属(PGE、Co 等)。关键金属因具有极度耐热、 难熔、耐腐蚀以及优良的光电磁等独特性能，在新能源、新材料、信息技术等 新兴产业和国防军工等行业中具有不可替代的重大用途. 随着科技和新兴产 业的发展，未来几十年全球对关键矿产的需求将迅猛增长，供需矛盾将日益突 出. 以美国、英国及澳大利亚为首的西方国家，基于其国家战略安全，率先制 定了各自的关键矿产发展战略, 并启动了关键矿产重大研究及勘探计划, 旨在 减少因关键矿产资源供应链中断而带来的国家安全与经济发展隐患，保障关 键矿产资源的稳定供给. 面对迫切的新兴产业资源需求和严峻的国际资源竞 争态势, 迫切需要加大科技创新力度, 为保障我国关键矿产资源的安全供应提 供科技支撑。在此背景下，国家自然科学基金委员会于 2019 年 7 月启动了“战 略性关键金属超常富集成矿动力学”重大研究计划，拟通过我国关键矿产资源 成矿规律、成矿作用和高效利用的综合研究，摸清我国关键矿产资源家底，创 新关键矿产成矿及分离理论，提升我国对关键矿产的控制力和话语权.

确定成矿元素赋存状态及其源-运-聚的过程是建立关键矿产成矿理论及 分离理论的核心. 然而, 与铁、铜等传统大宗金属相比，关键金属元素在矿床 中常具有“稀、细、伴”的特征, 通常含量极低, 独立矿物小而少, 不易被直接 观察到; 同时, 关键金属元素地球化学行为较为复杂, 矿化类型繁多, 成矿机 制多样, 认知难度大. 另一方面, 关键矿产是国际上最近提出的资源概念, 针 


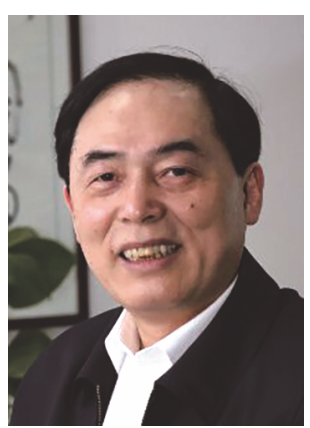

\section{陈骏}

南京大学教授, 中国科学院院 士, 国家自然科学基金创新研 究群体项目负责人, “战略性 关键金属超常富集成矿动力 学” 重大研究计划指导专家 组组长. 长期从事矿床学、矿 床地球化学及环境科学研究, 获国家自然科学二等奖 1 项。

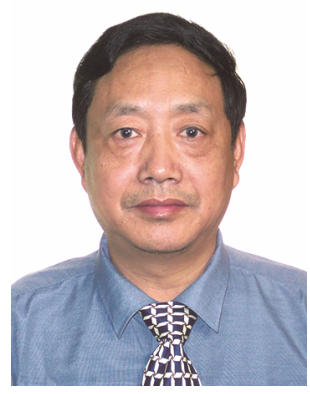

\section{准明国}

中国科学院地质与地球物理 研究所研究员、中国科学院 院士, 第三世界科学院院士, 国家自然科学基金创新研究 群体项目负责人。主要从事 变质岩石学、前寒武纪地质 和地球化学研究. 获何梁何 利科学技术(地球科学) 奖及 国家自然科学二等奖 2 项.
对此类矿床的专门研究刚刚起步, 且目前的研究多聚焦赋存状态、资源潜力等 方面, 针对成矿机理的研究较少, 认知程度较低. 因此, 相对于传统大宗金属 矿产来说, 关键矿产成矿及分离理论的研究面临着更大的科学挑战. 传统大宗 金属元素，其地壳丰度较高，正常富集几倍到几十倍即可成矿. 然而，大多数 关键金属元素的地壳丰度很低(一般为 ppm 级以下), 需要百倍甚至万倍的富集 才能形成可供开采的矿床. 显而易见，关键金属元素的成矿经历了“超常富集”, 因此, 低丰度金属元素超常富集成矿过程与驱动机制, 亦即低丰度金属元素超 常富集成矿动力学, 则成为关键矿产成矿学研究的核心科学问题. 那么到底是 什么地质过程驱动和地球化学机制导致这些关键金属元素的超常富集? 要回 答这一核心科学问题, 必须解决好以下三个关键科学问题: (1) 地球多圈层相 互作用与关键金属元素富集过程, 主要包括关键金属元素的地球化学行为、壳 幔及表生循环过程及机制; (2) 关键金属元素成矿机制与成矿规律, 主要包括 关键金属矿床形成及时空分布规律的地质及构造控制、影响矿化特征及矿化式 样(元素组合、矿物类型、赋存状态、矿床类型、定位空间、成矿专属性等)的 主控因素; (3) 关键金属元素赋存状态与强化分离机理, 主要包括关键金属元 素共生分异规律、共伴生富集成矿的主控因素、关键金属元素界面性质差异性 放大与强化分离新方法. 解决上述核心科学问题, 需聚焦以下科学前沿: （1）关键金属源区特征及金属转移机制; 主要包括矿床的形成是否需要源区金 属富集? 如需要源区金属富集，富集的机制为何? 部分熔融或水岩交互过程 中金属从源区转移的机制如何? (2) 关键金属的运移富集机制，主要包括迁移 关键金属的介质组成、迁移过程中的物理化学条件、迁移形式及富集情况等. （3）关键金属的沉淀机制，主要包括不同介质中关键金属的溶解度及其随物理 化学条件的变化情况、不同体系中控制关键金属溶解度变化的主要因素、不同 类型关键金属矿床的成因模式等.

在“战略性关键金属超常富集成矿动力学”重大研究计划启动之初, 特此 在《科学通报》上组织出版了“中国关键矿产资源研究”专辑, 系统梳理我国主 要关键矿产资源现状、研究进展及存在的主要科学挑战, 为中国关键矿产今后 的研究或项目部署提供综合性素材及框架性认识. 本专辑共收录 13 篇文章, 主要作者来自中国科学院、教育部及自然资源部等多个系统, 内容上几乎涵盖 了上述所有关键金属元素. 本专辑的编辑出版得到了南京大学、中国科学院地 质与地球物理研究所、中国科学院地球化学研究所、中国地质科学院地质研究 所等单位相关研究组的大力支持, 在此表示衷心的感谢. 希望通过本专辑的出 版, 能使读者了解我国关键矿产资源的现状、进展和挑战, 活跃本领域的交流 与合作，促进我国关键矿产研究的快速发展. 